\title{
Innovation spaces: Lessons from the United Nations
}

\section{Introduction}

In its seventieth year, the United Nations (UN) is now a complex web of agencies, programmes, funds and bodies. Its global operations have demanded tight organisational frameworks in order to function effectively, however it is often claimed that the UN's bureaucratic structure is a barrier to efficiency and innovation. With a global population that holds the UN to account for stimulating global progress, the organisation is faced with the challenge of addressing its barriers to innovation and efficiency. As has been stated, "a significant shake-up in the way that the UN does business is essential to keep pace with the significantly altered circumstances six decades after its founding" ${ }^{1} \mathrm{~A}$ recent movement towards employing innovation theory in humanitarian and development practice has led several UN agencies to rethink how they operate. Although some commentators may be skeptical that innovation is possible for such a large international organisation, this paper takes a fresh look at how the UN is dealing with contemporary global challenges in the $21^{\text {st }}$ century.

There is a vast amount of international relations literature that seeks to understand international organisations. ${ }^{2}$ Traditional approaches have perceived organisations as an outcome of intergovernmental decision-making. However over time there has been recognition that international organisations may not always be easily or effectively controlled by member states. ${ }^{3}$ For example, Loescher ${ }^{4}$ explores the fine line that the United Nations High Commissioner for Refugees (UNHCR) has trodden between serving refugees and meeting expectations from member states, which can at times present competing pressures. The global governance regime has been founded upon the concept of state sovereignty, ${ }^{5}$ but changing social structures around the world are giving rise to new conceptions of power and expertise. In a world where an adolescent has the power to send a digital message that influences thousands of people globally, traditional binaries between the governors and governed are starting to break down.

Organisations must now approach their work through a more individualised, agent-driven conceptualisation of their traditional 'beneficiaries', and understand how the constituencies that they serve engage with and shape their social and economic surroundings. The ability to centralise target populations in the design and decision-making process of humanitarian and development service will be crucial for organisations to generate improved outcomes and to better compete in the 'humanitarian marketplace'. ${ }^{6}$ Pressure is mounting from various sources, including both donors and target populations, for humanitarian organisations to provide services that more effectively reduce the gap between those with easy access to social and economic opportunities and those who are marginalised from opportunities. International humanitarian organisations must move beyond traditional, Foucauldian notions of governance and control, and empower those who have always been the 'governed', those who are facing the challenges themselves, to take a much more central, steering role in global governance. Organisations that fail to adapt their structures and approaches to meet these needs will soon become uncompetitive and redundant.

Disruptive practices could serve to break organisational path dependencies that have traditionally prevented some organisations from constructively critiquing and improving their own operations. 
This paper empirically explores the approach that United Nations agencies have started to take with 'innovation'. It highlights a recent trend in creating innovation spaces in the UN, and highlights ways in which this is both a driver and a consequence of a changing global governance regime, as the UN forges ahead towards its aim of a "Strong UN. Better World" (as of $30^{\text {th }}$ January on the United Nations website).

Within UN agencies, there has been a growing movement to establish 'innovation spaces' or 'innovation labs'. The labs are taking different forms - some virtual, others physical - and each is created with its own motivations unique to the context in which it operates. The use of the term 'lab', more commonly seen in the physical and natural sciences, conjures a sense of a safe haven for experimentation, focused problem solving and solution creation. In the UN, innovation spaces typically house experimental activity, and have varying degrees of autonomy from their parent agencies.

As laboratories for innovation have become part and parcel of innovation in the UN system, there is a pressing need to better understand what these labs can truly offer and whether they should be isolated, instead of mainstreaming innovation into an agency. The burgeoning establishment of labs demonstrates trust in this approach, but there is little evidence or analysis available to show why. This paper poses the following key questions to help unpack how innovation labs are taking shape and to inform lessons for future labs that aim to achieve a culture of innovation and improved humanitarian solutions: What form do innovation labs in UN agencies take? What motivated their initiation? What are their aims and objectives? What impact have they had and how is the impact being measured?

This research was conducted during the period between August 2013 to March 2014 by the authors, undertaking eight semi-structured interviews with staff and founders of innovation labs at several UN agencies. Due to the limited existing research into innovation labs, qualitative case studies were the chosen approach in this exploratory research. In-depth case studies were carried out at UNHCR Innovation and the United Nations Children's Fund (UNICEF) Innovations Lab Kosovo. Two weeks of fieldwork was carried out in Kosovo, involving observation and informal discussions. Shorter case studies were also conducted with the United Nations Development Programme (UNDP) and the UN Global Pulse through semi-structured interviews with key stakeholders. Additional data for all case studies was collected and analysed from online sources, articles and grey literature, as well UN working reports and guidelines.

The first section of this paper draws on the wider literature on innovation spaces, provides a brief overview of innovation in humanitarianism, and defines 'innovation spaces' as a foundation for this paper and wider research. We then explore the question of what form the labs take; mapping where they exist in the UN, documenting how they vary, and what makes them unique. ${ }^{7}$ This leads us to unpack the motivations behind these spaces, where we demonstrate that there are dual innovation imperatives for innovation labs, of firstly fostering a stronger innovation mindset and culture within the UN (which we describe as the 'indirect imperative'), and secondly supporting the innovation that exists among the communities for which the labs operate (the 'direct imperative'). ${ }^{8}$ Finally we explore what has been done so far to measure the impact of the labs, both on the culture of their parent organisations, and on the provision of services to target populations. 


\section{A Background to Innovation and Spaces}

Stemming from practice and models developed in management thinking for the private sector, a recent 'innovation turn' in the humanitarian sector has been met with enthusiasm ${ }^{9}$ and has offered a toolbox of ideas and methods for addressing the challenges faced by the sector. ${ }^{10}$ Early on in the innovation debate, there was a heavy focus on innovation for organisational improvement. ${ }^{11}$ Now there is also increasing interest in using innovation to foster the ideas and solutions from affected communities themselves. ${ }^{12}$

To date, various UN agencies have actively employed approaches drawn from innovation theory. This growing focus on innovation within UN agencies most prominently began with UNICEF's initiative to establish a dedicated innovation unit in 2007. Impressively, UNICEF has since established 14 innovation labs around the world ( $23^{\text {rd }}$ September 2015 , as listed on the UNICEF website), all driven by local needs. UNICEF has also created significant in-house research and development capacity for designing new products, as well as developing a set of open-source guiding principles for innovation and technology. Other UN agencies have followed UNICEF's lead. In 2012 the UNHCR launched its Innovation Unit, a small team that aims to 'amplify' the good practice already happening in the agency, as well as to 'connect' people to solve problems and 'explore' solutions with new partners. The World Food Programme (WFP) has also created two distinct innovation divisions - for programme-level innovation, and financial and systems-level innovation. A representative from WFP recently stated that innovation is on-going in the UN and that UN employees are "innovative by necessity". ${ }^{13}$

The Office for the Coordination of Humanitarian Affairs (OCHA), UNDP and others have also started to take on new innovation activities, although these have focused on events and networks more than innovation spaces per se. The World Humanitarian Summit planned for 2016 has thematic areas of work that include 'transformation through innovation', and The United Nations Economic and Social Council (ECOSOC) in 2013 also spotlighted the role of science, technology and innovation.

The movement towards using innovation spaces as a way of bringing together communities to collaboratively innovate is still in its infancy. ${ }^{14} \mathrm{~A}$ key staff member at UNICEF recently stated that "there isn't enough research to reflect and evaluate what they are doing" in their innovation work. ${ }^{15}$ Given that the field is in an early stage of development, the definition of innovation spaces and labs can be broad and varied. However, the existing definitions imply a new way of approaching work in what are often rigidly structured organisations, and reflect a challenge to the status quo of humanitarian and development work. UNICEF has defined its labs as:

open, collaborative incubation accelerators that bring business, universities, governments and civil society together to create sustainable solutions to the most pressing challenges facing children and youth. (31 $1^{\text {st }}$ October 2013, UNICEF stories website)

In this paper, we define innovation spaces as physical or virtual spaces that enable and support the creative problem-solving (technological or otherwise) of those who participate in the space. They do this through a range of activities and events, and may take the form of working units, labs, networks or centres that are established with a focus on supporting innovation within a particular organisation 
or environment. ${ }^{16}$ It should be noted that many of the innovation spaces within the UN use the term 'labs', so this paper will often refer to 'innovation lab' in a generic sense, recognising that labs are one subset of the umbrella term of innovation space.

Although humanitarian innovation theories and methodologies have been drawn directly from business practice, the use of innovation labs is still relatively new, even in the business world. ${ }^{17}$ Companies have recognised the value in creating out-of-office spaces in which employees can freely generate ideas and explore innovation processes. ${ }^{18}$ Whilst the physical space remains at the centre of many studies, research has shown that good facilitation of people within these spaces is key to achieving a lab's goals. ${ }^{19}$ Initially the attraction of innovation labs for businesses was to enable their workforce to be creative. As we explore later in the paper, this is one (but not the only) objective for innovation labs in the UN.

Businesses have also started to create 'Living Labs' as a more inclusive form of innovation labs, which aim to focus on gaining user-led insight to their innovation processes. The European Network of Living Labs (ENoLL) defines a Living Lab as "a real-life test and experimentation environment where users and producers co-create innovations" (taken from the ENoLL website). In other words, seeking users' feedback in order to improve products and services and increase their diffusion into the market. ${ }^{20}$ Likewise, some humanitarian organisations are engraining user-led insight into their innovation lab work in order to improve their own products and services - supporting users affected by crisis. In this sense the literature for innovation labs in a commercial setting, offers some insight into the application of innovation labs in humanitarian organisations. However, this literature is limited in its ability to speak to the fundamental principles that guide humanitarian action and align with its unique marketplace, in which international and non-governmental organisations have a very different relationship with their 'consumers' or stakeholders and beneficiaries. Interest in innovation labs has also taken shape in the public sector and policy work, which derives from a marketplace that is arguably more closely related to humanitarian aims. The first bespoke public policy innovation lab was Denmark's MindLab, which forced the Danish government to think more ethnographically about its approach to policy-making, by encouraging collaboration internally across departments and externally with communities. ${ }^{21}$ This lab has also recently been involved with UNDP (as noted below).

Despite the connections that can be drawn with research on innovation labs in the business and public policy spheres, there are unique characteristics of humanitarian work that warrant a fresh analysis of innovation labs in humanitarian organisations. Research from the humanitarian perspective is still limited, and this paper seeks to enhance understanding of the direct relevance of innovation labs to the humanitarian world, whilst at the same time further advancing research and practice that is relevant to a broader range of sectors.

\section{Mapping innovation spaces in the UN}

Our research revealed great diversity amongst innovation spaces within the UN system. Although they all broadly meet our definition above, the labs that we discovered have a diverse range of activities and aims; and vary in the way in which they interact with external actors, including the public, their target populations, and partners. The innovation spaces in the table below provide a 
snapshot of innovation activity within the UN (rather than a comprehensive representation of all UN agencies).

\begin{tabular}{|c|c|}
\hline UN Agency & Lab(s) \\
\hline $\begin{array}{c}\text { UNDP - Global Centre for Public Service } \\
\text { Engagement (GCPSE) }\end{array}$ & Public Service Innovation Lab (virtual lab) \\
\hline UN Global Pulse & New York Lab, Uganda Lab, Jakarta Lab \\
\hline UNHCR - UNHCR Innovation & $\begin{array}{c}\text { Thematic Labs (Learn, Home, Link, Energy, Self- } \\
\text { Reliance), UNHCR Ideas (both are virtual labs/ } \\
\text { networks) }\end{array}$ \\
\hline UNICEF - UNICEF Innovation & $\begin{array}{c}\text { 15 labs worldwide (including Kosovo, Burundi, } \\
\text { Zimbabwe, Uganda, Copenhagen, Armenia, } \\
\text { Sudan, Zambia) }\end{array}$ \\
\hline
\end{tabular}

Table 1: Example innovation labs in the United Nations

The UNICEF Lab in Kosovo was one of the earliest experiments in developing an innovation space within the UN. It was set up in 2010 in response to the immense population of youth in Kosovo, and the core aim of the Lab is to create a generation of young people who are equipped with the skills and ambition to try to solve their society's problems. ${ }^{22}$ The significant degree of autonomy of the Lab allows it to focus on the grass-roots level, to reach more adolescents and young people from the most marginalised families. ${ }^{23}$ With this autonomous model the Lab staff can also devote time to considering the more ideological aspects of innovation within UNICEF and methods to stimulate organisational change, to the advantage of both UNICEF and its target population. ${ }^{24}$

An important element for several of these UN innovation spaces is their partnerships with local NGOs. These external actors have been said to "often combine forces to put forward new information and ideas, push for new policies, and mobilize public opinion around UN deliberations and operations". ${ }^{25}$ It has been clear from our research that many innovation labs in UN agencies rely on the partnerships and expertise of these types of partners. ${ }^{26}$

These partnerships take different forms but are based on the sharing of networks, resources and in some cases physical space. For example, the UNICEF Innovations Lab Kosovo is partnered with the Peer Educators Network (PEN), which provides the Lab with links into networks of marginalised youth, who are the target population of the Lab. These networks are absolutely crucial to the work of the Lab, as they allow the Lab to reach deeply into communities and design its work alongside the end-user. ${ }^{27}$ Many labs also benefit from open innovation with the private sector, partnering to exchange knowledge and resources. For example, UNICEF's Labs have drawn on toolkits from private companies, such as Open IDEO (an online idea collaboration platform) and collaboration with Frog Design (a private design consultancy). ${ }^{28}$ 
Some spaces facilitate and operate through partnerships more so than innovating themselves. UNDP's Public Service Innovation (PSI) Lab is one example of this. Working as a subset of UNDP's Global Centre for Public Service Excellence, the PSI Lab aims to bring social innovation and design thinking to the attention of policy-makers, engaging them in public service reform. The Lab acts as a liaison between the public service (for example, it is partnered with the Singaporean Government) and innovative thinkers such as MindLab, a 'cross-governmental innovation unit' that brings together businesses and citizens to innovate for positive social change. Together, these actors explore new tools and methodologies that can shake up bureaucratic structures and enable them to provide better services.

It is clear that UN innovation spaces are extremely varied, and aim to meet specific organisational and local demands. At UNICEF, the 'Do-it-yourself-guide' has been created to help UNICEF offices establish their own labs, and also as a way to share UNICEF's learning more broadly to the public. ${ }^{29}$ Each UNICEF Lab operates quite autonomously and there is a great range of work undertaken technology, data, youth advocacy, emergency response, supply chain processes etc. - depending on the needs of the communities in which they work. ${ }^{30}$

At the moment, the models for innovation spaces have developed organically within their various departments, and there is no single UN model or form for innovation spaces. This behavior has also been apparent in the past for innovation in the public sector. ${ }^{31}$ However for the UN some agencies are seeking opportunities to streamline across the organisation and avoid duplication of work. This is reflected in the development of the UN Innovation Network. ${ }^{32}$ UN Global Pulse also stated in 2011 that it was looking to streamline innovation across the UN, drawing together the various units working on innovation into one unit so that agencies can better learn from each other's innovative practices.

There are instances of UN innovations labs collaborating together on projects, but this is not widespread. The UNICEF Innovations Lab Kosovo worked with UNHCR for its birth registration project (using a rapid SMS platform to register births that would otherwise not be recorded in Kosovo), amongst others. Given that labs often establish strong networks within communities 'on the ground', they would be useful spaces and sources of information for various UN agencies. There could be potential for labs to be less UN agency-specific and to feed innovation work into multiple UN agencies simultaneously. The UN Global Pulse Labs are perhaps the closest to this approach, as they support multiple UN agencies, however their focus is limited to data. However whilst collaboration is key to innovation, caution should be taken not to 'UNify' and centralise innovation space models, since this could not only burden innovation labs with unnecessary top-down bureaucracy, but would also crucially undermine the importance of the end-users, who should be the heart and soul of innovation spaces, determining their specific direction.

\section{Variations in the nature of space}

The meaning attributed to 'innovation space' varies widely across UN agencies - from physical spaces, to virtual networks, to the label 'lab' being used to describe creative processes and ideas. There is no one-size-fits-all form that a lab should take. This section analyses the variation in forms of innovation spaces within the UN. It becomes evident that innovative thinking and methods are often more important than the physical space of a lab, if such a physical space even exists. Whilst 
the location and design of a physical lab space are incredibly important for facilitating innovation, fieldwork is often just as crucial, especially to ensure a strong human-centred approach. ${ }^{33}$ At the Global Centre for Public Service Excellence at UNDP, the physical space is prominent and the process and environment for innovation are described as more important than the final results:

How labs approach decision-making is more important than the end-result [...] the logistical arrangements of design labs are as relevant as the type of expertise they manage to mobilize. ${ }^{34}$

However, the physical nature of the space has not always been the main focus or contributor to enabling collaborative innovation to occur. A few of the UN agencies have recognised that networks and personal relations are sometimes more important than physical space, and have therefore established virtual spaces to support innovation. For example UNHCR has labelled some of its groups of practice 'labs'; such as their Learn Lab and Energy Lab. ${ }^{35}$ Although these are not physical spaces like the UNICEF labs, they do form a type of innovation space - in this case they are virtual networks. The UNHCR labs connect staff globally around their respective thematic areas and facilitate ongoing innovation projects in the field. Likewise, despite it not being a physical space with permanent staff, UNDP decided to use the label 'lab' for a series of prototyping events because this work represented a creative exploration of new approaches to public service innovation. ${ }^{36}$

Many target populations of development and humanitarian agencies are highly mobile and interact with their communities, cities and spaces in kinetic, often transient ways. This liminality calls for a dynamic provision of services. There can be a tendency for international civil society to perceive the communities with which they work as static in their movements and their interactions with support systems. However, a number of UN innovation labs are beginning to respond to the mobility and dynamism of end-users in more effective ways.

Online tools and technologies have been one of the strategies that innovation labs employ to better communicate and collaborate with a dynamic constituent. For example 'UNHCR Ideas' is an online platform, or a virtual innovation space, where invited users can contribute their ideas in relation to a specific problem. Whilst there are still some barriers faced by certain partners and refugees in connecting to the internet, UNHCR Ideas has so far managed to reach many field locations. ${ }^{37}$ Conclusions from a review of the pilot of the online platform found that the tool was well received by its users and has helped to raise the profile of innovation within the agency. ${ }^{38}$

A number of labs are conceived of as both a physical and a virtual space, bringing various actors together in meeting places, both online and in person. ${ }^{39}$ The UNICEF Labs in Kosovo and Burundi provide examples. Some labs undergo a transition from a virtual to a physical space. UNICEF Innovation South Sudan was initiated as a 'pop-up' virtual structure, however eventually it is intended to become a permanent physical space. The spatial transition can also occur in the reverse direction, from physical to a greater focus on the virtual, which has been the case with the UNICEF Innovations Lab Kosovo. The Kosovo Lab has taken a number of forms over its period of existence. Originally, it was a large open space that was purposefully designed. There were flexible glass walls dividing the space so that everyone could be part of the activity happening at all times and feel connected to it. There was plenty of light and flexible furniture (such as bean bags), and the Lab was a comfortable, inviting space into which young people could walk off the street and give life to their 
ideas. ${ }^{40}$ This directly reflected the Lab's aim to be a space that its target population could easily access, bringing ideas, issues and energy. The Lab was intended to be flexible enough to respond immediately to the demands of young people.

The Innovations Lab Kosovo has since moved out of this space and is currently situated across two sites: an office in the centre of Pristina, and a function space elsewhere. The function space is used for large events like workshops and social innovation camps, but otherwise the physical space no longer plays a core role in the work of the Lab. Neither the function space nor the office is very accessible for young people to just 'walk in off the street', so the Lab is now most accessible to young people through online networks. Therefore, the 'Lab' now really means the online social and digital space, as well as the experimental mentality in the office. ${ }^{41}$ Evidently, the objectives and focus of the Lab in Kosovo have changed over time, for various reasons both within and outside of the Lab's control. The Lab has been flexible in adapting to external changes and modifying its approach, whilst still maintaining its core principles, including, and perhaps most importantly, human-centred design. Such structural malleability is important for labs to best respond to the methods of engagement that are preferred by the end-users.

Another strategy employed to respond to end-user agility is ensuring that labs are themselves physically mobile - for example through the use of remote staff and pop-up locations. Mobile and transient end-points allow the Lab to reach end-users who are physically remote or without access to online networks, and to work with them in a flexible, deeply engaged way. This mobile strategy will not necessarily be appropriate for other labs with different objectives. The nature of a lab's 'space' and the strategies that it employs to engage with end-users should depend on the specific aims and constituencies of a particular lab. For example, labs that exist to connect parties that traditionally consider their objectives to be in tension with each other (for example, activists and government, or the public and private sector) might also be better served by a physical location where the neutrality of the convening body reinforces its role as facilitator. ${ }^{42}$ Lab teams should be reflecting upon the nature of their location and space, and given that the lives and needs of endusers are kinetic, it is crucial that the nature of a lab space is constantly re-evaluated to ensure that it is not out of step with the people it exists to serve.

\section{What makes a lab unique?}

In understanding the make-up of innovation spaces, it is useful to analyse how innovation spaces differ from standard UN offices, and therefore what added input they can provide in improving the UN's work. One element that sets innovation spaces apart from their non-innovation UN office counterparts is their deliberate and determined prioritisation of flexibility, whereas other departments are often more restricted by strategic plans and institutional bureaucracy. ${ }^{43}$ Innovation labs do not have all the answers to the new problems that the world is facing, however they are trying new approaches, forging new networks and calling on a broader range of disciplines to try to deal with the changing world. ${ }^{44}$ Part of this changing world is the erosion of traditional binary distinctions - rights-holders versus duty-bearers, experts versus non-experts, haves versus have-nots - and innovation labs aim to harness the break-down of these traditional binaries. ${ }^{45}$ By trying new techniques and disrupting methods that have come to be seen as the norm in service delivery, innovation spaces can overcome inertia that UN agencies can find difficult to erode. ${ }^{46}$ 
This flexibility is abundantly clear at the UNICEF Innovations Lab in Kosovo. The Lab works within communities, responding to issues on the ground as immediately as possible, rather than following an agenda set by UNICEF headquarters months or even years earlier. The Lab is using new approaches to communicate rapidly and effectively with its target communities, and working through very horizontal relationships. ${ }^{47}$ Many innovation spaces have the potential to transform the roles of the traditional "beneficiaries" of UN work so that they can actively contribute and guide project design rather than remaining at the receiving end of activities. ${ }^{48}$ Compared to many UN agency offices, UN innovation spaces often take more of a back-seat role and let their destiny be guided by the people who best understand the problems - those who are actually experiencing them. ${ }^{49}$ Thus, it is clear that innovation spaces are fundamentally different to traditional UN agency offices because the perspective from which they are approaching issues (that is, the perspective of the end-user) means that they are understanding demands on UN services that were not previously captured, and responding to them with new tools and a more fluid, less risk-averse mentality. ${ }^{50}$

Innovation labs are spaces where_'admitting failure' is welcome and encouraged. The UNICEF Innovations Lab in Burundi changed its focus quite dramatically after realising that the focus of its projects was misaligned with community needs. One of the Lab's core projects is UReport, which is an SMS system to facilitate communication across the country on topics of concern to the people. The Lab found that UReport was not having as great an impact as it could have done because only approximately $3 \%$ of people in Burundi have access to electricity from the grid, meaning that it was very difficult for them to charge their mobile phones. The Lab therefore turned its focus towards energy, even though this was not a traditional area of expertise for UNICEF. The Lab learnt from the weakness in its original project design, and this adaptation of focus demonstrates the Lab's approach of responding actively to the needs of the community on the ground. ${ }^{51}$

Of course, the degree to which such flexibility is practically possible in UN innovation spaces varies. A certain degree of autonomy is required for an innovation space to operate responsively to immediate needs and in an experimental manner. ${ }^{52}$ Even those spaces that do have significant autonomy (such as UNICEF Innovations Lab Kosovo) are nonetheless not immune to structural and financial constraints. Likewise, whilst UN Global Pulse aims to innovate from the grass-roots, it nonetheless responds to an annual research agenda, which would undoubtedly constrain its flexibility.

\section{The imperatives of innovation spaces}

Although commercial innovation labs have used 'Living Labs' to focus on user-led innovation, ${ }^{53}$ the main imperative for these organisations is to increase profitability of the company and its products. For humanitarian organisations, the incentives are clearly different, which leads to different processes and outcomes. We have observed two means by which innovation labs are striving towards their goal of finding creative solutions to a range of existing problems in the humanitarian and development sectors. These means are described here as innovations imperatives. The first is to create organisational change, and the second to enable a community to lead its own change.

In relation to the first imperative, innovation labs support the growth of an innovation culture that helps shift bureaucratic stasis within large organisations. ${ }^{54}$ Underlying such organisational cultural change is the idea that it will ultimately improve the organisation's ability to have a positive impact 
at the community level. In other words, a more innovative and flexible organisation will be better able to provide services for its target population. This may be thought of as an indirect approach generating organisational cultural change in order for the organisation to then ultimately achieve better outcomes in terms of its mission. This indirect approach of generating organisational cultural change is certainly not easy. The work of innovation spaces inherently disrupts the status quo, and can therefore be controversial within UN agencies. General organisational cultural change is difficult at the best of times, but mainstreaming a disruptive, innovative mentality can prove especially difficult if it is perceived to be an injection from the outside, rather than arising from the core of an organisation itself.

The second imperative that guides innovation labs is to support the ideas, and facilitate the projects of affected communities themselves, thus generating positive change for the target population through a more direct route. This direct imperative to support a community's initiatives is reflected in the way that Josh Harvey, head of UNICEF's Innovations Lab Kosovo, describes the ultimate goal of the Lab: to "work ourselves out of a job". ${ }^{55}$ The Innovations Lab Kosovo seeks to give the community the tools to create their own solutions and improve their own futures, such that they eradicate dependencies on humanitarian or development sector support, thus disrupting the traditional models of humanitarian and development aid.

The concept of direct and indirect innovation by humanitarian agencies is depicted in the model below. The imperative to build a culture of innovation within a UN agency should improve the organisation's ability to develop humanitarian solutions, which will in turn positively impact communities on the ground. The imperative to support the innovation of affected communities themselves impacts humanitarian solutions more directly, as this eliminates the prior step of generating organisational change.

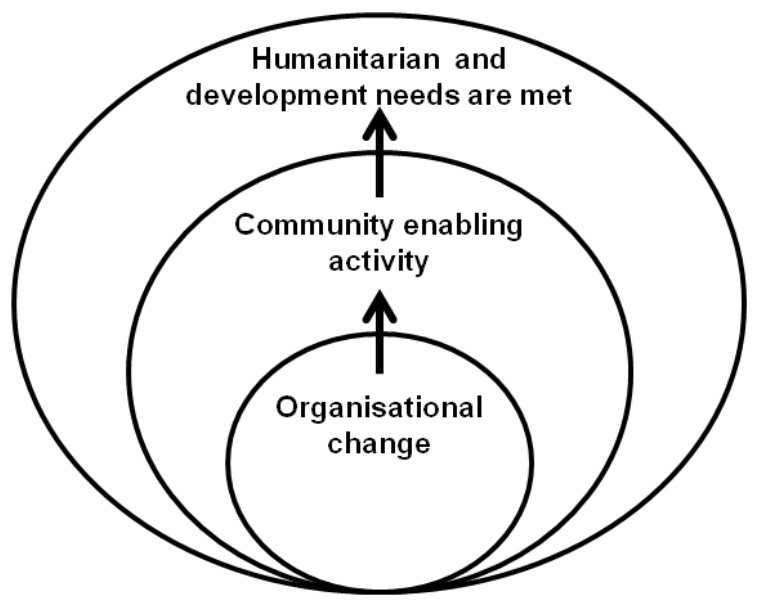

Figure 1: Direct and indirect innovation

The ideas captured by the terms 'direct' and 'indirect imperative' have been framed previously as 'two worlds' of humanitarian innovation: top-down innovation to improve organisational response and 'bottom-up' innovation that facilitates the innovative activity of traditional beneficiary populations. ${ }^{56}$ We have observed that these two theoretical worlds of innovation play out in the practice of UN innovations labs, which employ a range of activities and tools to simultaneously push for 'top-down' and 'bottom-up' innovation. 
1) Organisational change (Indirectimperative)

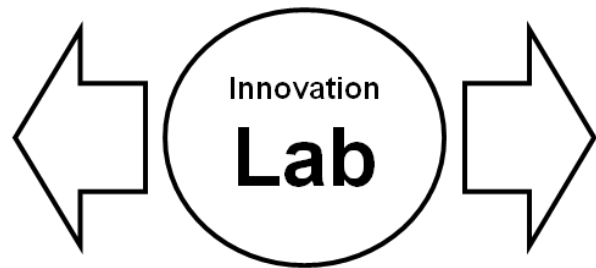

2) Community enabling (Direct imperative)

Figure 2: Dual imperatives of a UN innovation lab

To bring to life how the innovation labs are meeting these two imperatives, the image below illustrates a number of innovation lab activities on a spectrum between supporting the community directly in their own innovations, and focusing first on organisational change, to ultimately better support the community.

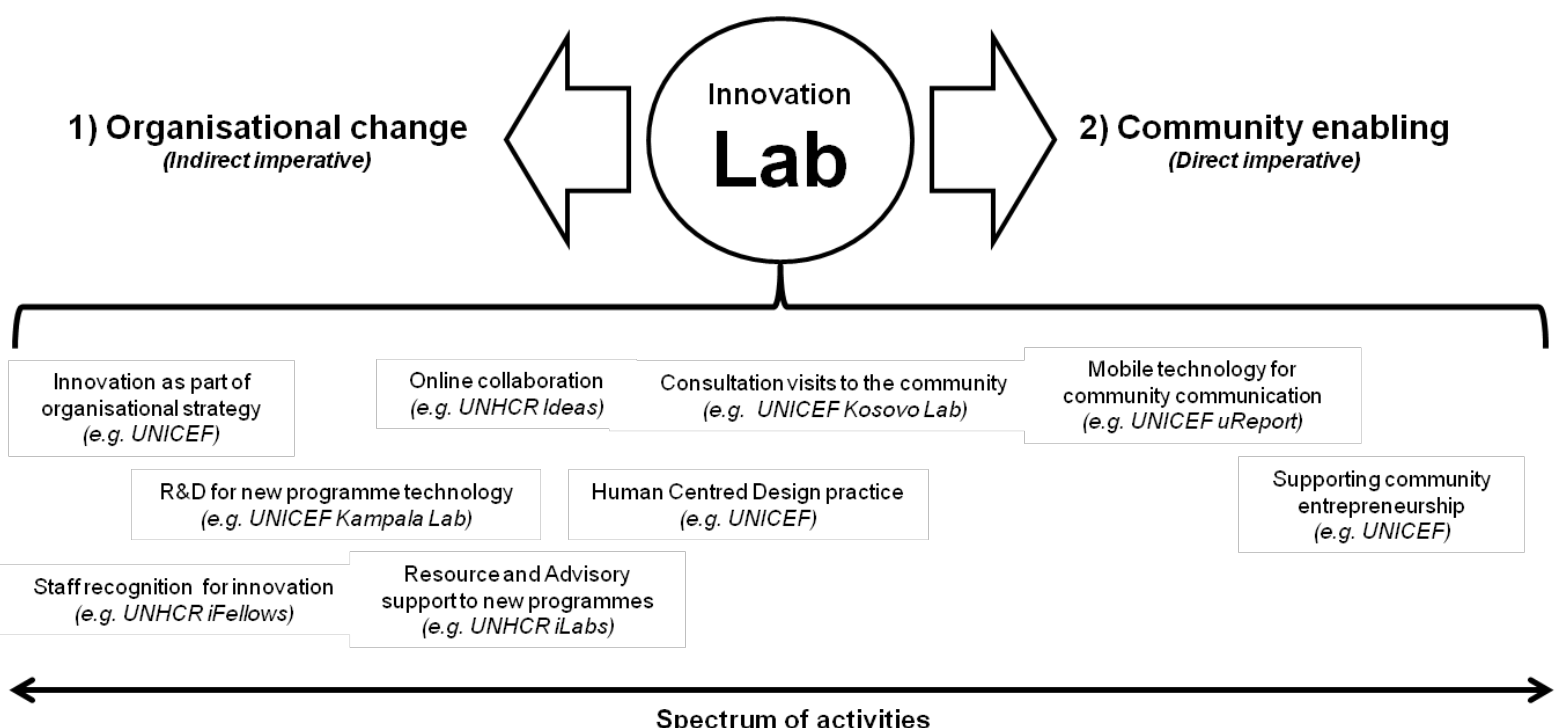

Figure 3: Innovation lab activities

On the left of the spectrum, UNICEF has now included innovation in its organisational strategy, with the core aim of creating organisational change. On the right-hand side, UNICEF's UReport project directly supporting the community to act. In the middle of the diagram, the 'UNHCR Ideas' online collaboration tool is used to try and create a culture of innovation within the agency, and also acts as a platform where staff, partners and beneficiaries can share their ideas, targeting both direct and indirect imperatives.

Like many development and humanitarian actors, UN agencies have historically struggled to effectively engage communities in their work on the ground..$^{57}$ Innovation labs have started to implement activities that show promise for more dynamically working hand-in-hand with communities. As shown by Figure 3, the tools and activities of the labs are not clearly delineated and relevant only to one imperative or the other. Rather, they sit on a spectrum in terms of their relationship to the two imperatives, and the two imperatives naturally interact and influence each other. That said, it is important that innovation lab teams are conscious of the separation and balance between the two imperatives, so that the direct imperative, with the ultimate goal of 
facilitating bottom-up change, is not lost amidst the aim of achieving the first imperative of organisational change.

The direct imperative of strengthening the capacity of communities to "create solutions to their own pressing problems" (UNICEF USA website), is a slower process and a long-term goal for many UN innovation labs. In the meantime, there is a need for labs to continue working towards the indirect imperative, of improving the ability of UN agencies to provide better services within the existing model of humanitarian and development aid. Innovation labs therefore sit as necessary 'half-way houses' for the time being, working simultaneously through both their direct and indirect imperatives to effect positive change. In that sense, innovation labs fulfill an important role in bridging the two worlds of humanitarian innovation, which is an aim that is unique to the humanitarian world, as compared with innovation labs in the private and public sectors.

\section{Impact of innovation spaces}

As the innovation movement grows, there is increasing impetus to understand how the outcomes of innovation practice may be measured and proven to work. Studies have shown that whilst key stakeholders of labs in the private sector focus on idea generation, there are concerns from users that ideas are not translated into implemented outcomes. ${ }^{58} \mathrm{UN}$ innovation labs and spaces are aware of the need to better measure what they are doing, ${ }^{59}$ but only just starting to take this into action. Given the flexible and failure-friendly nature of innovation lab work, monitoring impact against traditional criteria often used in bureaucratic organisations can pose problems. ${ }^{60}$ In a sense, innovation spaces are being forced to innovate in the way they measure impact and learn from their work, using trial and error. This is unsurprising, given the nature of the projects that they are monitoring, which employ new techniques, equipment and actors.

The UNHCR provides one example of the potential for UN innovation teams and labs to generate new solutions for monitoring and evaluation. UNHCR Innovation in its first two years has already been successful in obtaining buy-in from within the organisation and is now overwhelmed with requests for input into projects across the agency. ${ }^{61}$ The team has been aware of the need to capture, learn from and communicate its impact. Since its inception in 2012 the innovation team has documented its activity, using it to reflect, and adapt what they do. However, UNHCR Innovation is now seeking to develop more strategic and structured ways of measuring its work. The interest in measuring impact at UNHCR Innovation hasn't come from requirements by donors, but is instead driven by the team - as a way to learn and plan for the future, and to also remain accountable to various stakeholders.

The impact of some projects is measurable in terms of the amount of financial support obtained and the extent to which the initiatives are demanded elsewhere. UNICEF's UReport was developed in Uganda but now scaled to other countries. Scale may be one common way to measure successful impact, although even if scale can be measured, the ultimate impact of projects on society is often very difficult to measure. As one example, the Innovations Lab Kosovo is faced with the challenge of accurately measuring an increase in confidence amongst young people who have been involved with the Lab's Youth Advocacy Platform. The Innovations Lab Kosovo draws on a mix of quantitative and qualitative (for example ethnographic) methods of measurement, recognising that both are necessary to give a more complete picture of progress. ${ }^{62}$ Importantly, the Innovations Lab Kosovo 
very deliberately prioritises constant reflection and measurement by all members of the lab, rather than waiting until the end of a project or strategic agenda period to realise that aspects could have been improved. ${ }^{63}$

The UN innovation spaces are themselves capturing as much of their progress as they can, which for the large part has been shared openly in an attempt to allow others to learn from their work. However, given that the labs are still very young, the progress on measuring the impact of innovation labs in the UN is still limited and there is a lack of clarity around impact measurement. One question that should be posed is how innovation labs can prevent their measures becoming bureaucratic and stifling the innovation that they work so hard to progress? To move forward on this debate, it will be important for UN innovation spaces to maintain their autonomy and to generate new ways of thinking about what, how and why they measure their impact.

It is important to note that impact will take a different form for the direct and indirect innovation imperatives. Tools used for measuring how far organisational change has been achieved will not look the same as those used to measure how far a community's own innovation has been supported and achieved change at the grassroots. Remaining accountable to the community is something that will be key in innovation work. It will be important to ensure measurements are not lost in upward accountability only, as many attempts at measuring impact in the sector have done in the past. Allowing communities to define the measures of impact is something that has been advocated in humanitarian evaluation, ${ }^{64}$ so labs might be able to help bridge the relationship gap and work handin-hand with communities in re-defining what humanitarian impact really means.

\section{Conclusion and further research}

This paper is the first empirical study to reflect upon the nascent growth of innovation labs in the humanitarian sector and specifically within the UN. It demonstrates that several UN agencies have shown a strong commitment at their top-level management to focus on innovation as a key priority moving forward. Staff members in the Senior Leadership Development Programme at UNICEF are exploring how to make innovation the 'new normal'. ${ }^{65}$ For UNHCR, innovation activity is becoming increasingly integrated into field projects and sectors of work. On top of this, the number of UN innovation labs is growing. UNICEF has recently opened new labs, and new spaces are touted in other agencies too.

Innovation Labs have proven their ability to deepen relationships with affected communities as well as to foster innovation among new stakeholders and participants. One aspect that sets innovation labs apart from many physical science laboratories or commercial innovation labs is that they are not quarantined or isolated from the outside world. The opposite is true - they often seek to develop the deepest relationships with the outside world possible, interacting side-by-side and within communities. They are ensuring that they stay lean and flexible, often dealing with transient and mobile communities. Moving forward it will be crucial that innovation labs do not focus so much on organisational change that they pay mere lip service to the direct imperative of facilitating change from within communities.

It is crucial to remember that the local context is at the core of a lab's work, and what works in one country will not necessarily work in others. Therefore, of necessity, there should be vast differences 
between innovation spaces. Indeed, the differences in aims, methods, and design of space that we discovered across the UN innovation spaces reflects the specific needs of each location. Therefore, any push for a streamlined model of an innovation space or innovation processes should be resisted, to preserve the primary importance of focusing on the local context and keeping the target population at the centre of programme design. In this regard, research on innovation labs in the humanitarian space requires new methods in order to analyse the connection between innovation labs and their environment. This is something that could also help to inform research on innovation labs in other sectors, where observation of this connection is under-developed.

When innovation spaces are operating separately from programme offices, and calling upon new disciplines to develop solutions, they are at times required to translate their work into a language and format that can then be injected back into the agency's core programs. ${ }^{66}$ It should be questioned whether having these separate spaces is actually then beneficial to the process of organisational cultural change, if innovation is being injected from the outside rather than being indigenous to the development of all programmes within an organisation. It is possible that the importance of innovation spaces as bounded, separate entities will dissipate and become a passing phase, if UN agencies are successful in mainstreaming innovation within every aspect of their core processes and programs. In that case, there may not be a need for separately defined innovation 'labs' or 'spaces'. However, until innovation cultures do become more mainstream within the UN, innovation labs might be a necessary 'halfway house'.

Whilst the forms that UN innovation spaces take and the motivations for their existence vary, one thing is clear: there are impressive positive impacts from the work of innovation spaces across the UN, which should be celebrated and built upon for the future. As the movement grows, it is important that the teams in innovation labs regularly step back and reflect. There should certainly be critical analysis of two key issues: firstly, what the imperatives of the particular lab are, and whether these are being met in a balanced way; and secondly, whether the isolated innovations lab model is the most effective in achieving a UN agency's ultimate aim of improving social conditions. This paper has demonstrated that the innovation lab model can be an effective tool, at least for the time being. Innovation spaces constitute a significant step on the pathway towards the ultimate goal of communities having the resources and capacity to generate solutions for themselves. With constant critical reflection and further analytical and critical research on the topic, innovation spaces have the potential to be a formidable force for social change. 


\section{Notes}

${ }^{1}$ Daws and Weiss, "World Politics."

2 Keohane, "The demand for international regimes," 325-355; and Keohane, "After Hegemony;" and Mearsheimer, The tragedy of great power politics.

3 Hawkins et al., "Delegation under anarchy," 3-38.

${ }^{4}$ Loescher, "The UNHCR and world politics," 33-56.

${ }^{5}$ Weber and Biersteker, "Sovereignty as Social Construct."

${ }^{6}$ Weiss, Humanitarian Business; and Gottwald, "The Humanitarian Marketplace."

${ }^{7}$ The mapping and analysis in this article is not intended to present a comprehensive view of all of the innovation activity in the UN system, but rather a taste of some of the activity that we captured under the rubric of innovation spaces. The analysis of the labs that are mapped in this paper reveals some of the nuances of diversity in physical forms and the types of collaboration that the spaces facilitate.

${ }^{8}$ Research was undertaken through online sources, articles and grey literature, as well as observational field work visits to labs, and 8 semi-structured and open interviews with staff and others involved in a selection of UN innovation labs. Field visits and deeper research into some of the labs are presented as illustrative case studies in the paper. This work represents findings from research conducted in 2014-15, but labs and innovation spaces are inherently fast-changing and flexible, so it is possible that the aims, activities etc of the spaces may have changed since the time of writing.

${ }^{9}$ White, "Turning ideas into action."

${ }^{10}$ Ramalingam et al., "Innovations in international humanitarian action"; and Betts and Bloom, Humanitarian Innovation; and Tidd and Bessant, Managing Innovation.

${ }^{11}$ Betts and Bloom, "two worlds of humanitarian innovation."

12 Betts et al., Refugee Innovation; and Betts and Bloom, Humanitarian Innovation.

${ }^{13}$ Conte, "Humanitarian Innovation and the United Nations."

${ }^{14}$ Berkhout and Tiesinga, Labcraft.

${ }^{15}$ Campo, "Humanitarian Innovation and the United Nations."

${ }^{16}$ See note $14,37$.

${ }^{17}$ Magadley and Birdi, "Innovation Labs," 315-325; and Lewis and Moultrie, "The Organisational Innovation Laboratory," 73-83.

${ }_{18}$ Moultrie et al., "Innovation Spaces," 53-65.

19 Lewis and Moultrie, "The Organisational Innovation Laboratory," 73-83.

${ }^{20}$ Bergvall-Kåreborn et al. "A Milieu for Innovation", 6-9.

${ }^{21}$ Carstensen and Bason, "Powering Collaborative Policy Innovation."

${ }^{22}$ Harvey, Personal communication.

${ }^{23}$ Mugaju, Personal communication.

${ }^{24}$ See note 22.

${ }^{25}$ Weiss, What's wrong with the United Nations, 9.

${ }^{26} \mathrm{iHub}$ Malagasy is a partnership between UNICEF Madagascar and a local independent lab. The UNICEF Lab in Chile is also in collaboration with Socialab, an innovative NGO that aims to reduce poverty and social inequality.

27 See note 22 .

${ }^{28}$ At time of writing the UNICEF web page shows South Sudan's Innovation Lab activities as on hold due to conflict.

29 'UNICEF, Innovation Labs.

${ }^{30}$ Lepage, Personal communication.

${ }^{31}$ Carstensen and Bason, "Powering Collaborative Policy Innovation." 4. 
${ }^{32}$ UNHCR, "UNHCR Standing Committee."

${ }^{33}$ See note $14,46$.

${ }^{34}$ Allio, Design Thinking.

35 UNHCR Innovation, "2013 Annual Report."

${ }^{36}$ Husar, Personal communication.

${ }^{37}$ Bosley, "UNHCR Ideas." 15-16.

${ }^{38}$ Bloom, "UNHCR Ideas."

${ }^{39}$ See note 30.

${ }^{40}$ Zymberi, Personal communication.

${ }^{41}$ See note 22.

${ }^{42}$ Ibid.

${ }^{43}$ See note 34.

${ }^{44}$ See note 22.

${ }^{45}$ Ibid.

${ }^{46}$ Ferreira and Armagan, "Using social networks theory," 168-184.

${ }^{47}$ Hajdari, Personal communication.

${ }^{48}$ See note 36.

${ }^{49}$ See note 22.

${ }^{50}$ See note 30.

${ }^{51}$ Ibid.

${ }^{52}$ See note 22.

${ }^{53}$ Bergvall-Kåreborn et al. "A Milieu for Innovation", 6-9.

${ }^{54}$ Aleinikoff, "Innovation - what, why and how," 8-10; and UNICEF Copenhagen Lab, Personal communication.

${ }^{55}$ See note 22.

${ }^{56}$ See note 11.

${ }^{57}$ Brown and Donini, Rhetoric or reality.

${ }^{58}$ Magadley and Birdi, "Innovation Labs", 315-325.

${ }^{59}$ See note 22.

${ }^{60}$ See note 14.

${ }^{61}$ Earney, Personal communication.

${ }^{62}$ See note 22.

${ }^{63}$ Ibid.

${ }^{64}$ Anderson et al., Time to listen.

${ }^{65}$ See note 15; and Lake, "Executive Board Meeting report."

${ }^{66}$ See note 22.

\section{Bibliography}

Aleinikoff, T. A. "Innovation - what, why and how for a UN organisation." Forced Migration Review Supplement: Innovation and Refugees, September (2014): 8-10.

Allio, L. Design Thinking for Public Service Excellence. Singapore: UNDP Global Centre for Public Service Excellence, 2014. 
Anderson, M.B., Dayna Brown, and Isabella Jean. Time to listen: Hearing People on the Receiving end of International Aid. Massachusetts: CDA, 2012.

Bergvall-Kåreborn, B., Carina Ihlström Eriksson, Anna Ståhlbröst and Jesper Svensson. "A Milieu for Innovation - Defining Living Labs." 2nd ISPIM Innovation Symposium, New York, 6-9, 2009.

Berkhout, R. and Hendrik Tiesinga, H. (eds.) Labcraft. London: Labcraft Publishing, 2014.

Betts, A. and Louise Bloom. "Humanitarian Innovation: The State of the Art". Occassional Policy Paper Series. New York: UNOCHA, 2014.

Betts, A. and Louise Bloom. "The two worlds of humanitarian innovation", Refugee Studies Centre Working Paper Series, no. 94. Oxford: Refugee Studies Centre, 2013.

Betts, A., Louise Bloom, and Nina Weaver, "Refugee Innovation: Humanitarian innovation that starts with communities." Oxford: Refugee Studies Centre, 2015.

Bloom, L. "UNHCR Ideas: Open innovation inspiring collaboration and new ideas within the UN." Oxford: Humanitarian Innovation Project, 2014.

Bosley, A. "UNHCR Ideas: an online platform for change". Forced Migration Review Supplement: Innovation and Refugees, September (2014): 15-16.

Brown, D. and Antonio Donini. "Rhetoric or reality? Putting affected people at the centre of humanitarian action". ALNAP Study. London: ALNAP, 2014.

Campo, S. "Humanitarian Innovation and the United Nations." at Humanitarian Innovation Conference. Oxford: University of Oxford, 2014.

Carstensen, H.V. and Christian Bason. "Powering Collaborative Policy Innovation: Can Innovation Labs Help?" The Innovation Journal: The Public Sector Innovation Journal 17, no. 1, article 4 (2012).

Conte, A. "Humanitarian Innovation and the United Nations." at Humanitarian Innovation Conference. Oxford: University of Oxford, 2014.

Daws, S. and Thomas Weiss. "World Politics: Continuity and Change Since 1945." Introduction in Oxford Handbook on the United Nations. Oxford: Oxford University Press, 2008.

Ferreira, M. and Sungu Armagan. "Using social networks theory as a complementary perspective to the study of organizational change." Brazilian Administrative Review 8, no. 2 (2011): 168-184.

Gottwald, M. "The Humanitarian Marketplace." UNHCR Working Paper no. 190. October 2010. 
Hawkins, D., David A. Lake, Daniel L. Nielson and Michael J. Tierney. "Delegation under anarchy: states, international organizations and principal agent theory." Chap. 1 in Delegation and Agency in International Organizations. Cambridge: UK, 2006.

Keohane, R. O. After Hegemony: Cooperation and Discord in the World Political Economy. Princeton: Princeton Paperbacks, 1984.

Keohane, R. O. "The demand for international regimes." International organization 36, no. 02 (1982): 325-355.

Lake, A. “Executive Board Meeting report.” UNICEF, 18 ${ }^{\text {th }}$ June. New York: UNICEF, 2013.

Lewis, M. and James Moultrie. "The Organizational Innovation Laboratory." Creativity and Innovation Management 14, no. 1 (2005): 73-83. doi: 10.1111/j.1467-8691.2005.00327.x

Loescher, G. "The UNHCR and world politics: state interests vs. institutional autonomy." International Migration Review 35, no. 1 (2001): 33-56.

Magadley, W. and Kamal Birdi. "Innovation Labs: An Examination into the Use of Physical Spaces to Enhance Organizational Creativity." Creativity and Innovation Management 18, no. 4 (2009): 315325.

Mearsheimer, J. J. The tragedy of great power politics. London: WW Norton \& Company, 2001.

Moultrie, J., Mikael Nilsson, Marcel Dissel, Udo-Ernst Haner, Sebastiaan Janssen and Remko Van der Lugt. "Innovation Spaces: Towards a Framework for Understanding the Role of the Physical Environment in Innovation." Creativity and Innovation Management 16, no. 1 (2007): 53-65. doi: 10.1111/j.1467-8691.2007.00419.x

Ramalingam, B., Kim Scriven, and Chris Foley. "Innovations in international humanitarian action". Chap. 3 In ALNAP 8th Review of Humanitarian Action. London: ALNAP, 2009.

Tidd, J. and John Bessant. Managing Innovation: Integrating Technological, Market and Organizational Change, 5th Edition. Chichester: Wiley, 2013.

UNHCR Innovation. “Annual Report 2013’. Geneva: UNHCR, 2014.

UNHCR Innovation, “UNHCR Standing Committee.” 5 March 2014.

UNICEF, "Principles for Innovation and Technology.” New York: UNICEF, 2014.

UNICEF, “UNICEF Innovation Labs: A Do-It-Yourself Guide.” New York: UNICEF, 2012.

UNICEF, “UNICEF Strategic Plan 2014-2017.” New York: UNICEF, 2014.

Weber, C and Thomas Biersteker. State Sovereignty as Social Construct. Vol. 46. Cambridge: Cambridge University Press, 1996. 
Weiss, T. Humanitarian Business. Cambridge: Wiley, 2013.

White, S. "Turning ideas into action: innovation within the humanitarian sector. A think piece for the HFP Stakeholders Forum." London: Humanitarian Futures Programme 2008.

Weiss, T. G. What's wrong with the United Nations and how to fix it. Cambridge: Polity Press, 2012. 